\title{
A study of menstrual hygiene management in urban and rural adolescent girls in Ambala (Haryana)
}

\author{
Shallu Garg ${ }^{1}$, Anu Bhardwaj ${ }^{2}$, Anshu Mittal ${ }^{3}$, Suresh Bhonsla ${ }^{4}$
}

${ }^{1}$ Postgraduate Student, Maharishi Markandeshwar Institute of Medical Sciences and Research, Mullana (Ambala); ${ }^{2}$ Professor, Maharishi Markandeshwar Instituteof Medical Sciences and Research, Mullana(Ambala); ${ }^{3}$ Professor and Head, Maharishi Markandeshwar Instituteof Medical Sciences and Research,Mullana(Ambala); ${ }^{4}$ Postgraduate student , Maharishi Markandeshwar Institute of Medical Sciences and Research,Mullana(Ambala)

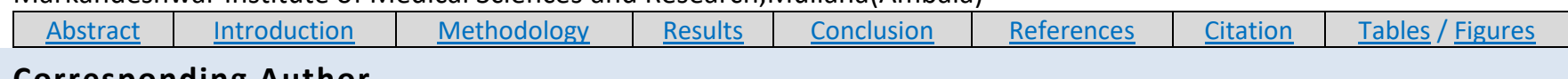

\section{Corresponding Author}

Dr Anu Bhardwaj, Professor, Department of Community Medicine, Maharishi Markandeshwar Institute of Medical Sciences and Research, Mullana (Ambala), Haryana

E Mail ID: dranubhardwaj78@gmail.com

\section{Citation}

Garg S, Bhardwaj A, Mittal A, Bhonsla S. A study of menstrual hygiene management in urban and rural adolescent girls in Ambala (Haryana). Indian J Comm Health. 2020;32(1):120-123.

Source of Funding: Nil Conflict of Interest: None declared

\section{Article Cycle}

Received: 14/09/2019; Revision: 05/01/2020; Accepted: 25/02/2020; Published: 31/03/2020

This work is licensed under a Creative Commons Attribution 4.0 International License.

\section{Abstract}

Background: Adolescent girls often lack knowledge regarding reproductive health including menstruation hygiene. Poor menstrual hygiene can be a precursor reproductive tract infections and even cancer cervix. Objectives: To study the menstrual hygiene management among rural and urban school going adolescent girls Material and Methods: A community based cross sectional study was conducted among 420 adolescent girls (10 - 19 years). A self-designed semi- structured questionnaire was used to study the knowledge and practise regarding menstrual hygiene. Results: Knowledge about menstruation before attainment of menarche was $69 \%$ in urban and $58.9 \%$ in rural. Mother was the main source of information. Still $23.6 \%$ girls were using cloth or towels as menstrual absorbent, and $26.6 \%$ girls in rural area were washing their menstrual absorbent to be reused.91.7\% and $81 \%$ girls had some restriction during menstruation Conclusion: Awareness in urban adolescent girls was more in comparison to rural girls. The usage of sanitary pads was similar in both rural and urban areas. Menstrual hygiene was better in urban than rural areas. It is imperative that adolescent girls be educated about the, significance of menstruation, and proper hygienic practices during menstruation. Sex education in school curriculum can help in resolving misconceptions about menstruation.

\section{Keywords}

Adolescent girls, Menstruation, Menstrual Hygiene, Restrictions

\section{Introduction}

Menstrual hygiene management is defined as 'Women and adolescent girls using a clean menstrual management material to absorb or collect blood that can be changed in privacy as often as necessary for the duration of the menstruation period, using soap and water for washing the body as required, and having access to facilities to dispose of used menstrual management materials' (UNICEF and WHO, 2014). However, menstrual hygiene is not just about the management of the menstrual period but also the need to address societal beliefs and taboos surrounding the issue. Menstrual hygiene depends upon the educational, socioeconomic, and cultural statuses of family. School curriculum also has some role in menstrual health.(1) Social prohibitions and the attitude of parents in not discussing the menstrual related issues openly has created less awareness among adolescent girls.(2) Due to the non-salient, unsaid but ironically understandable taboo about menstruation, females of all age groups don't talk of or seek early preparatory advice before menarche, and even treatment to health problems from concerned bodies related to menstruation.

Unsafe sanitary conditions and poor personal hygiene are mainly responsible for many of the gynaecological problems. Lack of hygiene during menstruation leads to increased incidence of infections. $(3,4)$ Vaginal infections mainly occurs as a result of growth of micro organisms, which in itself is, usually due to prolonged and frequent use of unclean napkins. $(5,6)$ Awareness and adoption of 
safe hygiene practices among adolescents play a significant role during menstruation as this makes the women less vulnerable to RTI. Millions of women suffer from RTI and its complications which further leads to transmission of infection to offspring.(1)Menstruation is a significant reason for school absenteeism and school dropouts.(7) Safe practices during menstruation right from childhood may helps in alleviating the sufferings of many women.(8)

\section{Aims \& Objectives}

To assess knowledge and practices regarding menstrual hygiene in district Ambala.

\section{Material \& Methods}

The present study was a cross sectional study among 420 school going adolescent girls in the age group of 13-19 years in rural and urban area of district Ambala, Haryana, India. Stratified random sampling technique was used for sample collection. To work out the required sample size the equation used is $n=z \alpha 2 p q / 12$

Where $z \alpha$ is standard normal variations for $95 \%$ confidence interval $=1.96$

$p=$ Prevalence of menstruation disorders i.e. is $21 \%$. (9)

$\mathrm{n}=$ Minimum sample size required.

$q=100-p$

I = Allowable error i.e. $20 \%$ of prevalence.

There were 134 government and 69 private coeducational schools in the District Ambala. A total of 9 schools with 50 students from each school were included in the study. As the number of schools in the government and private sectors were in the ratio of 2:1.

Clearance was obtained from the institutional ethics committee. Readiness to participate in the study was obtained by written consent from the participants after explaining the objectives of the study. A pre-designed, pre-tested semi-structured questionnaire was used. Care was taken to ensure privacy and confidentiality. The semistructured questionnaire included topics relating to knowledge regarding menstruation, source of information regarding menstruation and hygiene practiced during menstruation. Data obtained was analyzed using the SPSS Version 20, and findings were reported in the form of descriptive statistics.

\section{Results}

A total of 420 adolescent girls from rural and urban areas participated in the study. The overall mean age of the participants was 13.98 with a range of 10 -19years. The mean age of the urban adolescents was 12.39 years and that of the rural adolescents was 12.31 years respectively. It was seen that $97.2 \%$ of the girls in rural area studied in class 9 - 10, whereas $2.8 \%$ were from class $11-12$ and $79.2 \%$ of the urban students were from class $9-10$ and $20 \%$ from class 11 - 12 . In rural area majority of the girls $(86.5 \%)$ studied in Government schools whereas $51.2 \%$ of the girls in urban area studied in private schools. Mothers of most of the respondents were house wives.

About $69 \%$ adolescents in urban area were aware about menstruation as compared to rural area which was $58.9 \%$. The difference in the knowledge was significant ( $p$ value $<$ $0.05)$. It was found that the main source of information was mother $(62.6 \%)$ followed by teachers $(24.3 \%)$ and then friends and relatives (12.1\%). Mothers (60.1\%) and teachers $(71.6 \%)$ were the preferred source of information in rural area as compared to urban. In urban area friends (43.1\%) were also found to be a good source of information. A good number (83.7\%) of adolescents in urban area discussed their experience about menstruation with others as compared to adolescents in the rural area (73.8\%). About $45.5 \%$ of the girls had a normal reaction to menarche, $52.4 \%$ in urban area and $40.9 \%$ in rural area. $47.9 \%$ adolescents were depressed and $6.7 \%$ were scared of menarche. $74.3 \%$ adolescent girls used sanitary pads / tampons followed by $23.6 \%$ who used cloth /Towel and $21 \%$ used cotton as absorbent. It was observed that $84.5 \%$ of the adolescent used dustbin for disposal in urban area whereas only $71.8 \%$ adolescents in rural area used dustbin for disposal.26.6\% girls in rural area washed their used cloth for reuse as compared to $11.9 \%$ in urban area. $1.9 \%$ burnt their used material after use and $0.5 \%$ flushed them in toilet. The association between area and method of absorbent disposal was found to be significant $(p=0.001)$. It was concluded from the table 2 that in rural area $62.3 \%$ used only water to clean the genitalia whereas in urban area $64.3 \%$ of adolescent girls used both water and soap to clean. $1 \%$ girls do not even wash their genitalia during menstruation. It was observed that restrictions were same both in rural and urban area. Majority were related to visiting the religious place (84.15) followed by dietary restriction (48.2\%). $46.4 \%$ were considered dirty during menstruation.(Table 1) (Figure 1)

\section{Discussion}

Present study showed awareness about menstruation before attainment of menarche was higher in urban adolescent girls $69 \%$ as compared to rural girls $58.9 \%$. Similar study conducted by Adrija D et al (2012)(10) in West Bengal reported that $72.1 \%$ of the urban participants and only $39.1 \%$ rural participants had prior knowledge to menstruation. Kamath R et al(2013)(11) showed that only $33.27 \%$ and $35.82 \%$ of the urban and rural participants respectively had awareness about menstruation prior to menarche. The variation in the awareness was may be due to the difference in the socio cultural factors among the two populations, the educational status of the family and better exposure to media.

The present study showed that mother(62.6\%) was the main source of information regarding menstruation followed by teachers $(24.3 \%)$ and then by friends $(12.2 \%)$, 
similar finding were found in a study by Deo et al (2005)(12). This is in agreement with the study done in Gujarat by Tiwari et al(2006)(13) showing that the major source of information was the mother $(60.7 \%)$ followed by older sisters (15.8\%). Teachers and others (which included near and distant relatives) played a small role and the study done in Malaysia by Lee et al (2006)(14) showing Mothers were the most preferred persons the girls turned to for answers regarding menstruation. $54.5 \%$ girls had negative reaction to menarche like $6.7 \%$ scared (8 students in rural and 20 students in urban) and $47.9 \%$ were depressed. 103 girls in rural and 88 in urban gave a normal (positive) reaction to menarche. Negative attitude was higher in rural adolescents $59.2 \%$ as compared to urban adolescents $47.6 \%$. A study done by Kamath et al (2013) (11)and study by Shanbhag D et al (2012)(15) in Bangalore city found that a large majority of students experienced fear $44.1 \%$ followed by anxiety $26.1 \%$ during menarche. Tiwari $\mathrm{H}$ et al (2011) (13)found $28.3 \%$ felt ashamed, $12.6 \%$ felt guilty, $20.6 \%$ were feared. The reason for fear and anxiety may possibly be due to inadequate knowledge about menarche and menstruation.

In the present study $74.3 \%$ of the girls used sanitary pads as absorbent and $23.6 \%$ used cloth and $2.1 \%$ used cotton as absorbent material. Omidvar S et al(16)in 2010 also found that $68.9 \%$ girls regardless of the age used disposable pads and a small proportion (7.4\% and $19.1 \%)$ used cotton and cloth material respectively. S Senthil et al $(2016)(17)$ reported $90 \%$ of the girls did not had the habit of cleaning the genitals with soap and water regularly during the menstrual flow days and majority had the habit of disposing the pads (45\%) along with the routine waste and $32 \%$ told that they wash the cloth and reuse it, in present study $76.9 \%$ were disposing the pads in dustbin and $20.7 \%$ were washing the cloth for reuse, $1.9 \%$ burnt the used absorbent and $0.5 \%$ flushed it in the toilet. It was observed that in rural absorbent were reused more $(26.6 \%)$ than the urban area (11.9). It was observed that restrictions were same both in rural and urban area. Majority were related to visiting the religious place (84.15\%) followed by dietary restriction(48.2\%). $46.4 \%$ were considered dirty during menstruation. Paria et al (2017)(18) revealed different types of restrictions practiced during menstruation. $64.72 \%$ of urban and $78.57 \%$ of rural girls practiced different restrictions during menstruation. Another study in Haryana (76.4\%) girls had dietary restrictions, $85.5 \%$ girls were restricted to visit temples and $62.7 \%$ girls were prohibited entry to kitchen during periods.(19)

\section{Conclusion}

Awareness in urban adolescent girls was more in comparison to rural girls. The usage of sanitary pads was similar in both rural and urban areas. Menstrual hygiene was better in urban than rural areas.
It is imperative that adolescent girls be educated about the scientific facts of menstruation, physiological implications, significance of menstruation, and proper hygienic practices during menstruation. Sex education in school curriculum can help in resolving misconceptions about menstruation. Media can also play a significant role. Mothers should be motivated to break their inhibitions about discussing with their daughters regarding menstruation and menstrual hygiene. Social marketing can be used to advocate universal use of sanitary pads by all girls.

\section{References}

1. Dhingra R, Kumar A, Kour M. Knowledge and practices related to menstruation among tribal (Gujjar) adolescent girls. Ethno-Med. 2009;3:43-8.

2. Subhash B, Sushma S, Monica R, Nidhi R, Ketaki P, Suresh U. Menstrual hygiene: Knowledge and practice among adolescent school girls of Saoner. Nagpur district. Journal of clinical and diagnostic Research. 2011;5(5):1027-33.

3. Mehra S. Adolescent Girl: An Indian Perspective. [Internet] New Delhi: MAMTA Health Institute for Mother and Child [1995, Cited 2018, Jun 12] Available from : https://www.researchgate.net/publication/307175405_HEALTH_ AND_HYGENIC_PRACTICES_OF_ADOLESCENT_GIRLS

4. Margaret E. Watering the Neighbours Garden. [Internet] New Delhi: Population Council Regional office for south and east Asia [1997, Cited 2018, Jun 12] Available from:http://www.chsj.org/uploads/1/0/2/1/10215849/booklet8 The_emerging_agenda-adolescents.pdf

5. Paul D. A Report of an ICMR Funded Research Project: Knowledge and Practices of Adolescent Girls Regarding Reproductive Health with special Emphasis on Hygiene during Menstruation. New Delhi: National Institute of Public Cooperation and Child Development (NIPCCD), 2007.

6. New Delhi: National Institute of Public Cooperation and Child Development [Internet]. NIPCCD [2007, Cited 2018 , Jun 12] Available from : http://nipccd.nic.in/reports/eaghealth.pdf

7. Sudheshna R, Dasgupta A. Determinants of menstrual hygiene among adolescent girls. A multivariate analysis. National Journal of Community Medicine. 2012;3(2):294-301.

8. Roberts M ."Why puberty now begins at seven". [Internet] BBC News. [2005, Cited 2018, Jun 10] Available from : http://news.bbc.co.uk/2/hi/health/4530743.stm

9. Nair MKCC, Ranjith DS, Darwin M. .Indian J.Pediatr 2012;79:74 doi 10.1007/\&12098-011-04312.

10. Adrija D, Nirmalya M, Mousumi D, Jhuma S, Baijayanti B, Saraswati D. Menstruation and menstrual hygiene among adolescent girls $A$ school based comparative study of West Bengal, India: Global Journal of Medicine GJMEDPH. 2012;(5):50-7.

11. Kamath R, Ghosh D, Lena A, Chandrasekaran V. A study on knowledge and practices regarding menstrual hygiene among rural and urban adolescent girls in Udupi Taluk, Manipal. India.[Internet] Manipal education [2016,Feb 22, Cited 2018 ,Jul 22 ]. Available from :http://eprints.manipal.edu/eprint/145378.

12. Deo DS, Ghattargi $\mathrm{CH}$. Perceptions and practices regarding menstruation: a comparative study in urban and rural adolescent girls. Indian J Community Med. 2005;30:33-4.

13. Tiwari $H$, Tiwari R, Oza UN. Knowledge, attitudes and beliefs about menarche of adolescent girls in Anand district, Gujarat. Eastern Mediterranean Health Journal. 2006; 12(2):3-4

14. Lee HK, Chen PC, Lee KK (2006). Menstruation among adolescent girls in Malaysia: a cross-sectional school survey. Singapore Med J 2006; 47(10): 869-74.

15. Shanbhag D, Shilpa R, D'Souza N, Perception regarding menstruation and Practices during menstrual cycles among high 
school going adolescent girls in resource limited setting around Bangalore city, Karnataka, India. International Journal of Collaborative Research on Internal Medicine and Public Health.2012;4(7):1354 - 1362 .

16. Omidvar $\mathrm{S}$, Begum $\mathrm{K}$, Menstrual pattern among unmarried women from south India. J Nat Sci Biol Med.2011;2(2):174-9

17. Priya SS. Menstrual problems and hygiene among rural adolescent girls of Tamil Naidu. Indian Journal Of Obstetrics And Gynaecology Research 2016;3(2):126-131.
18. Paria B, Bhattacharyya A, Das SA. Comparative Study on Menstrual Hygiene Among Urban and Rural Adolescent Girls of West Bengal. Journal of Family Medicine and Primary Care. Oct 2014;3(4):413417.

19. Anuradha, Huchchannavar R, Chayal V, Chahal S. A Study on Menstrual Hygiene among Rural Adolescent Girls. Indian Journal Of Health And Wellbeing,2013; 4(9):1709-11

\section{Tables}

\begin{tabular}{|c|c|c|c|}
\hline Variables & \multirow[t]{2}{*}{ Rural N = 262} & Urban N = 168 & \\
\hline \multicolumn{3}{|l|}{ Source Of Information } & \\
\hline Mother & $158(62.7 \%)$ & $105(39.9 \%)$ & $\chi^{2}=0.002$ \\
\hline Relatives/Friends & $29(11.5 \%)$ & $26(15.5 \%)$ & $\chi^{2}=1.395$ \\
\hline Teachers & $73(29 \%)$ & $29(17.3 \%)$ & $\chi^{2}=7.512$ \\
\hline \multicolumn{4}{|l|}{ Experience With The Menstruation } \\
\hline Normal & $103(40.9 \%)$ & $88(52.4 \%)$ & \multirow{3}{*}{$\begin{array}{c}\chi^{2}=23.086 \\
d f=2 \\
p=0.000\end{array}$} \\
\hline Depressed & $141(56.0 \%)$ & $60(35.7 \%)$ & \\
\hline Scared & $8(3.2 \%)$ & $20(11.9 \%)$ & \\
\hline \multicolumn{4}{|l|}{ Material Used As Absorbent } \\
\hline Cloth/Towel & $63(25.0 \%)$ & $36(21.4 \%)$ & \multirow{3}{*}{$\begin{array}{c}\chi^{2}=.947 \\
d f=2 \\
p=0.000\end{array}$} \\
\hline Cotton & $6(2.4 \%)$ & $3(1.8 \%)$ & \\
\hline Sanitary Pads / Tampons & $183(72.6 \%)$ & $129(76.8 \%)$ & \\
\hline \multicolumn{4}{|l|}{ Absorbent Disposal } \\
\hline Dustbin & $181(71.8 \%)$ & $142(84.5 \%)$ & \multirow{4}{*}{$\begin{array}{c}\chi^{2}=15.937 \\
d f=3 \\
p=0.001\end{array}$} \\
\hline Burning & $4(1.6 \%)$ & $4(2.4 \%)$ & \\
\hline Washing & $67(26.6 \%)$ & $20(11.9 \%)$ & \\
\hline Flushed In The Toilet & $0(0.0 \%)$ & $2(1.2 \%)$ & \\
\hline \multicolumn{4}{|l|}{ Material Used To Clean Genitals } \\
\hline Water & $157(62.3 \%)$ & $59(35.1 \%)$ & \multirow{3}{*}{$\begin{array}{c}\chi^{2}=31.191 \\
d f=2 \\
p=0.000\end{array}$} \\
\hline Water And Soap & $92(36.5 \%)$ & $108(64.3 \%)$ & \\
\hline Do Not Wash & $3(1.2 \%)$ & $1(0.6 \%)$ & \\
\hline \multicolumn{4}{|l|}{ Restriction During Periods } \\
\hline Yes & 231(91.7\%) & $136(81.0 \%)$ & $x^{2}=10.494$ \\
\hline No & $21(8.3 \%)$ & $32(19.0 \%)$ & $d f=1 \quad p=0.001$ \\
\hline \multicolumn{4}{|l|}{ Types Of Restrictions } \\
\hline $\begin{array}{l}\text { Dietary/Working In The Kitchen/ Handle } \\
\text { Pickle ( } N=203)\end{array}$ & \multicolumn{2}{|c|}{$122(48.4 \%)$} & $81(48.2 \%)$ \\
\hline To Take Bath $(\mathrm{N}=45)$ & \multicolumn{2}{|c|}{$24(9.5 \%)$} & $21(12.5 \%)$ \\
\hline To Visit Temple/Religious Place(N = 352) & \multicolumn{2}{|c|}{$212(84.1 \%)$} & $140(83.3 \%)$ \\
\hline Considered Dirty(N = 174) & \multicolumn{2}{|c|}{$96(38.1 \%)$} & $78(46.4 \%)$ \\
\hline
\end{tabular}

\section{FIGURE 1 SHOWING REACTION TO MENARCHE}

\section{Reaction To Menarche}

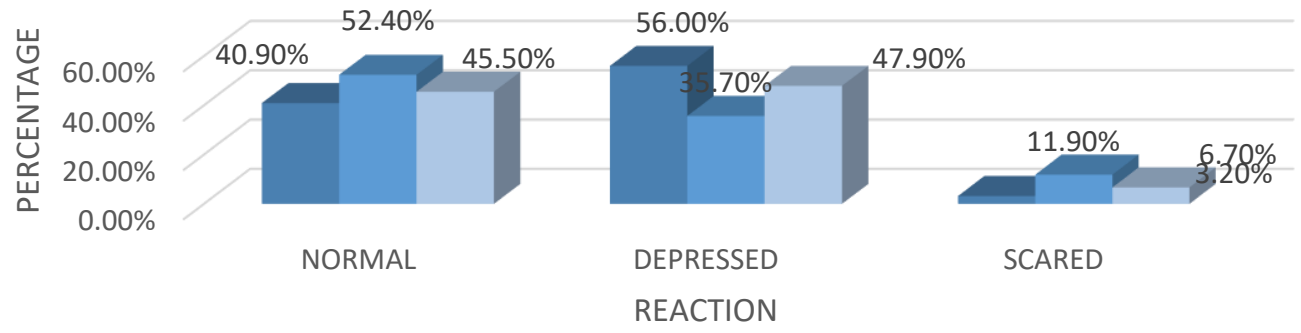

- RURAL IURBAN 